\title{
Synthesis of Hexagonal Bar Shape of ZnO Particles by Using Hydrothermal Treatment
}

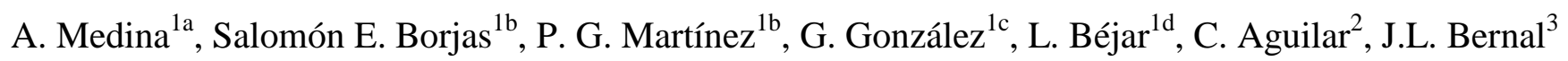

${ }^{1 \mathrm{a}}$ Instituto de Investigaciones Metalúrgicas, ${ }^{1 \mathrm{~b}}$ Instituto de Física y Matemáticas, ${ }^{1 \mathrm{c}}$ Facultad de Ciencias Físico y Matemáticas, ${ }^{1 d}$ Facultad de Ingeniería Mecánica, Universidad Michoacana de San Nicolás de Hidalgo, Morelia, Michoacán, México, C.P. 58000

${ }^{2}$ Depertamento de Ingeniería Metalúrgica y Materiales. Universidad Técnica Federico Santa María. Av. España 1680, Valparaíso, Chile.

${ }^{3}$ Automotive Mechanics Department. Universidad Politécnica de Pachuca. Zempoala, Hidalgo. México

In the last decade, the $\mathrm{ZnO}$ have took bigger importance because it is widely used as additive in several materials and products including plastics, ceramics, glass, cement, rubber lubricants, paint, adhesives, sealant, pigments, fire retardants [1]. Recently, it has also received special attention in applications such as heat-protecting windows, optoelectronic, gas sensing, transparent electrodes and solar cell applications [2]. $\mathrm{ZnO}$ is a versatile semiconductor material with a wide direct band gap of 3.3. eV and has been produced with different morphologies like wires, tubes, belts, bows, rods, rings, springs, stars, flowers, sheet networks, disks, columns, needles, and nuts [3]. Different synthesis process of $\mathrm{ZnO}$ have been used; however, both the effect of the temperature treatment and $\mathrm{Zn}$ source on the $\mathrm{ZnO}$ morphology by using hydrothermal method has not been studied. In this work, zinc nitrate hexahydrate (SigmaAldrich, purity $99 \%$ ) was used. Firstly, $5.95 \mathrm{~g}$ of $\mathrm{Zn}$ source was dissolved in $21.62 \mathrm{~g}$ of distilled water. Then, a second solution was prepared by dissolving $0.80 \mathrm{~g}$ of $\mathrm{NaOH}$ in $21.62 \mathrm{~g}$ of distilled water. The second solution was added slowly to the first solution and stirred for $30 \mathrm{~min}$. The resulting suspension with the molar composition of $\mathrm{Zn}$ source: $\mathrm{NaOH}: \mathrm{H}_{2} \mathrm{O}=1: 1: 120$ was hydrothermally treated in an autoclave at $160{ }^{\circ} \mathrm{C}$ for 1 day under static conditions. The synthetized particles were analysed by X-ray Diffraction (XRD), field emission scanning electron microscopy (FE-SEM) and dispersive energy spectroscopy (EDS). The results showed the formation of $\mathrm{ZnO}$ hexagonal crystal structure which can appreciate in figure 1 . The image 2(a) show the morphology of the $\mathrm{ZnO}$ hexagonal particles with a $5 \mu \mathrm{m}$ of large and $2 \mu \mathrm{m}$ of thickness and the figure 2(b) shows that the hexagonal particles are formed by $\mathrm{Zn}$ and $\mathrm{O}$ elements. The molar ratio of $\mathrm{Zn}: \mathrm{NaOH}$ of $1: 1$ was determinate in the formation of hexagonal shape of $\mathrm{ZnO}$ crystals by using hydrothermal method at high temperature aged obtained a new synthesis procedure for $\mathrm{ZnO}$ hexagonal particles by controlling its homogeneity, morphology and bar size of the particles.

References

[1] Y.Zhang, et al, Nanoscale Res. Lett. Volume 3 (2008) p. 201

[2] Daniel Vanmaekelbergh and Lambert K Van Vugt, Nanoscale Volume 3 (2011) p. 2783

[3] Kushwaha et al, AIP Advances, Volume 3 (2013) p. 042110-1. 


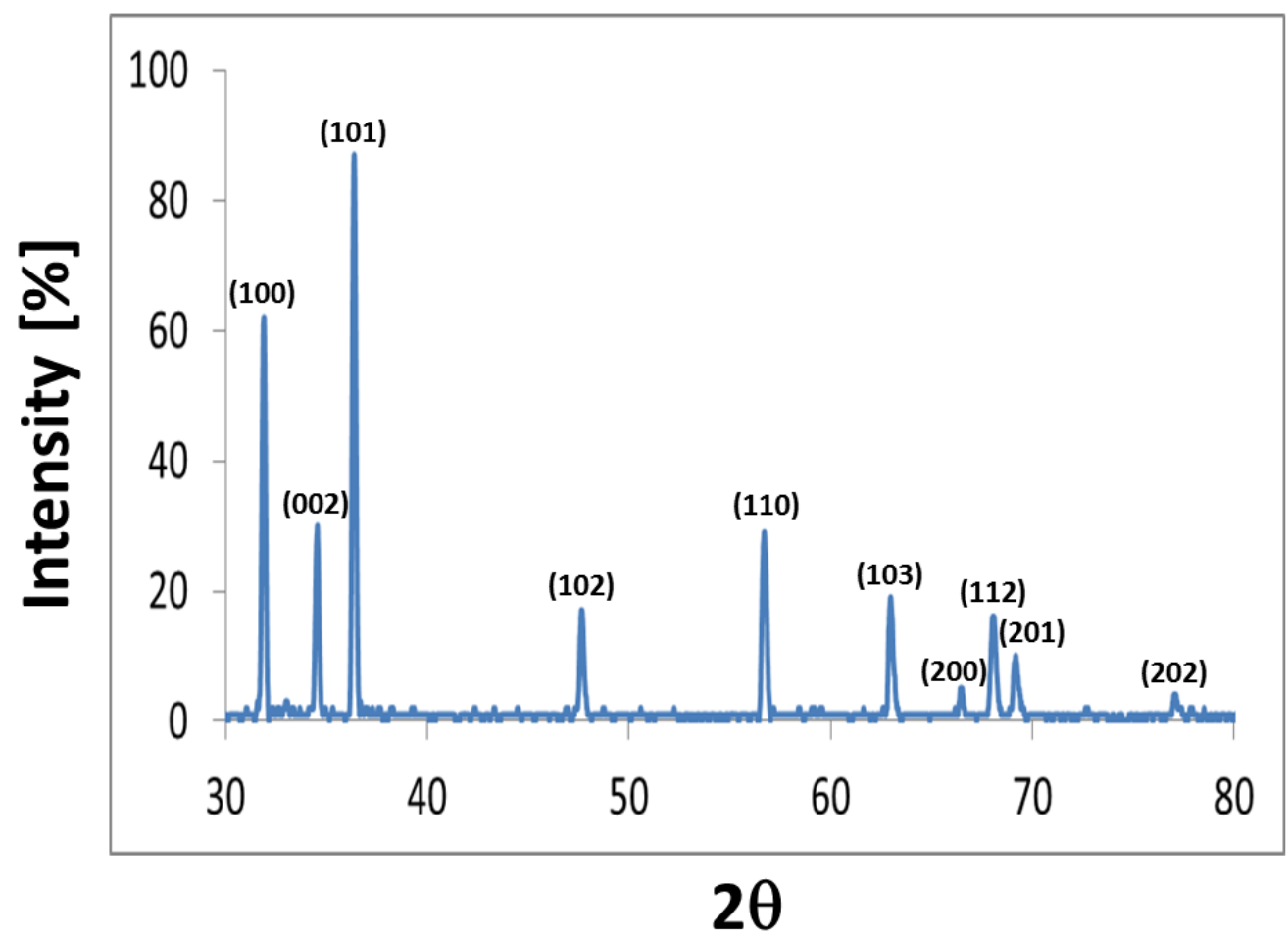

Figure 1. XRD pattern of $\mathrm{ZnO}$ particles synthesized at $160{ }^{\circ} \mathrm{C}$.
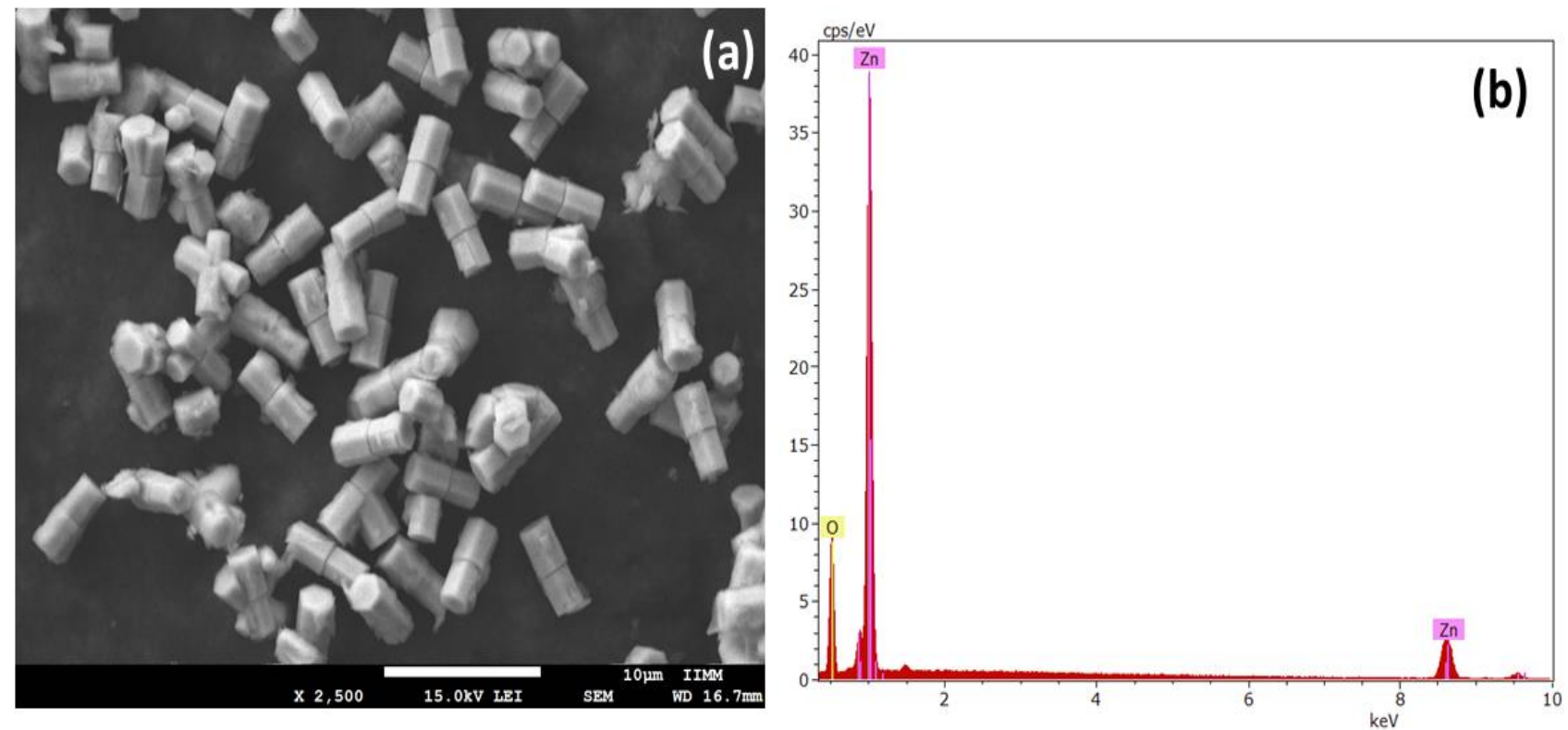

Figure 2. a) SEM image of $\mathrm{ZnO}$ hexagonal particles, b) EDS spectrum from the hexagonal particles. 